\title{
Concepts of Project Forecasting in the Formation of the Architectural Space of the Future
}

\begin{abstract}
Natalia Saprykina ${ }^{1, *}$
${ }^{1}$ Moscow Architectural Institute (State Academy), Moscow, Russia

*Corresponding author. E-mail: nas@markhi.ru

ABSTRACT

The article is devoted to the urgent problem of identifying the latest scientific concepts and trends in architecture, which can influence the formation of new approaches to the creation of habitat in architecture theory. The leading approach to the study of this problem is based on the use of historical and modern experience of architectural futurology, as well as the methods of project forecasting used for the prospective development of spatial habitat Future. The ideas about the recent spatial concepts in the architecture are being considered, both for modern conditions and for the projected future. The materials of the article and the findings can be useful for use in theory and practice of the formation of the habitat of the future, as they reveal completely new opportunities in architectural activities.
\end{abstract}

Keywords: architecture of the future, design forecasting, architectural futurology, information modeling, retro futurism, parametric modeling, dynamic adaptation, virtual reality, integrated systems

\section{INTRODUCTION}

Architecture in connection with the changes taking place in society, poses the task of science to identify newly emerging architectural spaces, stimulates the practice of inventing modern structures and materials, as well as construction technologies.

\section{A. The relevance}

Identification in architecture of the latest scientific concepts and trends that can influence the formation of new approaches to the creation of habitat in its theory becomes relevant. This is confirmedly by the use of historical and modern experience of architectural futurology, as well as project forecasting techniques used for the prospective development of the spatial habitat of the future.

The design-experimental futurological developments and the architecture theories address only ideas about spatial concepts, both for modern conditions and for the projected future. This necessitates the identification of new principles of approach to the analysis and formation of the spatial habitat of the future based on the methods of project the forecasting. The solution to the scientific problem in question is timely and relevant, as it allows revealing the potential possibilities of the architecture. The results

*This paper was funded by the Program of Fundamental Researches of the Ministry of Construction, Housing and Utilities of the Russian Federation and the Russian Academy of Architecture and Construction Sciences 2020, the Research Project 1.6.5. of the study can become a generator of new information, social and cultural innovation.

\section{B. Problem statement}

The purpose of the article is to present the results of the analysis of new approaches to the formation of habitat in the theory of architecture, using the experience of architectural futurology and fundamentally new modern scientific trends. This is because in the face of new areas of knowledge, the development of high technology and dynamic changes in the development of society, there is a need to constantly adjust the role of architecture and identify concepts formation of spatial habitat in the context of the latest paradigms.

In today's complex political, economic, social, and other processes, it is important to take in architecture the innovative project forecasting, which synthesizes the latest areas of science [1]. In this regard, there is a need to identify ways and techniques for the formation of habitat space in futurological studies, which are in modern architecture practically not used.

\section{FUTUROLOGICAL TRENDS AND THE FUTURE DEVELOPMENT OF THE ARCHITECTURAL SPACE OF THE FUTURE}

Exploring developments of the artificial habitat of the future, which using for these purposes existing studies of promising trends in architectural futurology, 
allows us to reveal the specifics of the approach to solving these problems in the following areas.

\section{A. Architectural futurology as a story of the future or a warning}

In both the historical period and now futurology attracts the attention of many scientists, experts, politicians and other experts. Their natural interest is to study alternative models of the future, to analyze social, economic, cultural factors and the consequences of the technological revolution [2].

Among the various types of manifestations of futurology, architectural utopias and dystopia occupy a special place. Utopian thought draws closer to the projects thinking, both at the design level and at the implementation level, allowing stimulating heuristic search. Dystopia as the opposite of the image of the desired ideal object of utopia, can also act as an imagewarning, suggesting the possible consequences of unmanageable development of certain trends of existing reality [3]. In the context of the problem at hand, another technology foresight of an alternative future, such as retro foresight, cannot be noted. Utopias can be retrospective when they are based on the projection of the present images of the "beautiful past" or on ideas about the "desirable future" [4].

Although the results of futurology can only be verified by the methods of waiting for the future, some scientific methods can be used in modern forecasting.

When quantifying the result, as a future, the method of prediction is called extrapolation, on the basis of which there is not a sufficiently accurate description of the model of the future. In futurology, as a rule, calculated methods are not widely used. The easiest way is to implement the method of individual expert evaluation, when the forecast is used either directly by the opinion of competent experts, or the forecast is made on the basis of an analysis of such opinions.

However, serious studies are more likely to use a collective peer review method in the exchange of experts' views, but it involves many intermediate forms. One of the most popular among them is the Delphi's method, in which sociologists conduct a survey of a group of experts in several rounds. One of the possibilities of systematizing expert assessments is create of so-called the morphological box [5].

There are three main methods of futurological forecasting: extrapolation, modeling and examination. Thus, the evolution of future prediction technologies has evolved in a very specific direction: from individual skill through collective skill and individual intuition to collective intuition.

\section{B. Approaches to the formation of architectural space in futurology as a powerful creative stimulus: technologies for predicting the future}

Today, no developed country is complete without research on the future, which mobilizes people to find ways to adapt society to new conditions. Therefore, the search for a new way of life, always associated with the appropriate level of quality of life, is constant. Interest in the design and forecasting of the cities of the future, which emerged at the beginning of the 21 st century, is being revived again today. The futurological works performed in conceptual form are trying to find a way out in solving the most pressing problems of modern cities. Analysis of these concepts and proposals can be useful for the creative and practical activities of architects and professionals.

There are four ways in human activity related to foresight [5]: forecasting, planning, futurology and foresight-technology. According to Balatsky E.V., forecasting is an exercise in determining future trends in the study area of the study based on an analysis of its condition in the past and present. Planning involves developing plans for the future of the research area, as well as measures to ensure that the plans are implemented. Futurology is an area of knowledge to determine the future development prospects of society. Forsyth, as a special technology the development of the field of research in the future, develops measures "to ensure the movement of society along the chosen trajectory on the basis of public consensus" [5].

It should be noted that the above-mentioned technologies predicting the future have an organic connection with each other, despite the differences between them. One type of prediction of the future grows on the basis of the previous one.

The foresight-technology system makes the transition from passive futurological foresight of the future to its active design and, "being in common with forecasting, planning, futurology, differs from them in that it is a process, and not a toolkit" [6]. The use of Forsyth technology allows us to describe and explore the vision of development prospects in the process of selforganization, which allows you to quickly transform and respond to new challenges.

The development of new forecasting technologies, such as foresight, and the creation of a diverse range of expert systems to assess various phenomena is an extremely significant innovation in modern science. This kind of foresight is fundamentally different from traditional forecasting and planning procedures. It involves identifying key areas of critical technology that will identify global challenges and even threats [7].

All the science of forecasting is an indispensable part of such a new and important discipline as the theory of decision-making. The problem of 
predictability includes the study of the features of forecasting as a special scientific study, the principles of optimal selection of forecasting methods, ways to assess the reliability of forecasts, principles of use for development Forecasts.

Among the ways of modeling some aspects of historical processes are offered as a variety, imitation modeling, which formalizes of information about the system under study, in general, structural-logical form. This approach allows radical formatting of the scientific information space and is a prerequisite for scientific futurological research [8].

\section{Architecture of the future: reflecting the development of science and technology as identifying "alternative opportunities"}

Identifying progressive trends in the study of architectural futurology by analyzing modern design futurological proposals and developments has allowed identifying innovative forecasts, the latest scientific concepts and trends in the organization spatial habitat [9].

The theoretical concepts and progressive trends that have emerged in the study of modern scientific paradigms, techniques, techniques and ways of organizing dynamic space in futurology, reveal their use in architecture in context follow-through.

Theories of complexity, catastrophe and chaos led to the conceptual and methodological foundation of a new science based on the paradigm of nonlinearity. Within this direction, the world as a multitude of systems is evolving. Each system lives by the laws of self-organization and experiences periods of stability and leaps and bounds in a different state.

The paradigm of complexity in the science of complex systems is evident in the non-linear architecture, which uses the method of kinematic section, fractal formation in land-formed architecture, and variable (flowing) fractals in the organization of dynamic space [10].

In dynamic form formation, non-linear architecture is a new direction with a new ordering tactic founded on so-called non-geometric forms. It aims to reach a qualitatively new stage of particularly clear ordering, including many theoretical concepts, for example, the concept of "liquid" space, the "field" of "formmovement" which in practice turns into a very complex program [10].

The kinematic section method, based on kinematic incisions, is a method of control and at the same time a method of generating shape when designing very large structures. This method, being introduced into the project consciousness, has become an important part of the new paradigm of "form-movement", "becoming", "fold" [11].

Fractal forms in land-shaped architecture are based on the intersection points of different geometric systems in such structures. It is built on the basis of systematic logic - it concerns the design itself, its perception, and orientation in it

According to the theory of chaos, the system can not only not break down through a state of instability, but also move to a new state thanks to the process of selforganization. The ability to organize itself and the desire to go through chaos to a higher order is a special feature of non-linear systems. It suggests that such systems have a specific quality of becoming integrity. We are talking about a new orderly architectural object that can constantly change simultaneously with the context, and a new principle of dynamic formation [12].

The constant completeness of the form with its constant variability speaks about the qualities of its unpredictability, infinity, special stability. The concepts of "liquid", "unstable" and "deep" space are introduced. Within the framework of the concept of non-linear architecture, the position of "architectural object as an ecosystem" deserves attention [12].

Concepts of the organization of architectural space in the context of futurological research show that the theory of architecture, enriched by new scientific paradigms, is trying to create new approaches to the modeling of space. When considering the principles of architectural space theory, it is noted that it was particularly noticeable to the turn to the use of ideas of the latest developments in the field of synergies, topological geometry, mathematics, microphysics, biochemistry, the new philosophy, etc. In various fields of knowledge, instability is the subject of interest in the construction of a variety of heuristic models.

The following concepts of architectural space organization are revealed in futurological design and experimental proposals [12]:

- The "linear" concepts of the design and spatial organization provide for the reserve stability of the object to critical conditions, originally laid down in the project and not implying quantitative or qualitative changes (e.g., the concept physical barriers and static adaptation).

- "Non-linear" concepts of fractal selforganization consider the organization of the architectural environment on the principle of fractal - a module that repeats at different levels and at different scales (for example, the concept of a rapidly constructed object, prefabricated and disassembled and modular house, open construction). 
- Concepts of “adaptive self-organization" imply the flexibility of structures in relation to critical environment conditions (e.g. dynamic adaptation and movement concepts). In determining the prerequisites for the formation of adaptive architecture, such concepts as dynamism, adaptation, variability, transformation, mobility due to the adaptability of the architectural form are considered [13].

Flexibility can be considered as physical mobility, and qualitative changes in the shape of an architectural object. It has been determined that from the point of view of adaptability of architectural objects there are static (unintended) adaptation and dynamic (intended) adaptation, the transformation processes of which can be acyclic (irreversible) and cyclical (reversible). Evolutionary transformation is the main way to implement acyclic processes, and cyclical processes ones are transformation and mobility [14].

\section{THE FORMATION OF A SPATIAL HABITAT FOR THE FUTURE BY PROJECT FORECASTING METHODS}

Among the technological concepts in the context of the problem under consideration in the organization of spatial habitat as an integrated self-adapting ecological system, special attention is paid to resource-saving concepts, concepts of reflection, as well as the reversibility and cyclicality of the system. There is a use of high-tech, such as "smart" buildings and structures with sensor and feedback systems that respond to changes in external impacts, as well as selfgrowing objects that are self-destructing and selfdegrading after the expiry of the building, etc.

\section{A. Arcological concepts as achieving a balance of technology and ecology: the formation of a "sustainable" eco-space}

Innovative eco-space concepts focus on the development and development of renewable energybased bio-tectonic systems. These include primary sources (solar, wind, hydro and geothermal, etc.) and secondary sources (biomass of natural and recyclable waste, dumped heat from electricity and nuclear plants, industrial and agricultural production).

Bio-tectonic directions and concepts offer a radical rethinking of the function of cities in the system of the whole planet and consider not only the technological component of achieving a positive balance between the city and the natural environment, but also sociopsychological factors. They do not offer specific design solutions, but only priority areas of urban planning. Each concept is a stage for the implementation of the follow-up (synergetic city — sustainable city noospheric city) [15].
In the context of the arcological paradigm, the direction of its development is manifested in conjunction with the development of innovative technologies, which determines the approach to further research as a balance of technology and ecology.

Trends that provide an ecological equilibrium: energy efficiency and energy conservation; use of renewable, environmentally friendly energy sources, ensuring the balance of the economy and the environment, the desire to harmonize the relationship between man, nature and architecture. Resource-saving concepts include maximizing resource conservation when building an energy-independent autonomous home and an energy efficient facility [16].

Environmentally sound design methods can be traced in the context of the concept of sustainable cities, which involves maintaining environmental integrity and natural resource reserves, combined with the use of new technologies and various Innovations. The concept of using renewable energy instead of natural resources creates a model of a city without carbon. Here, in the context of the concept of green architecture, the purification of air from cities by preserving and planting trees is achieved. It should be noted that "zero houses" are ahead of buildings that meet the requirements of any system with "green" standards [17].

Eco-polis as a new habitat is the idea of an ecological city in which the city is seen as a human habitat, providing it with an accessible fullness of direct communication with nature. In the formation of futurepolis as ecological re-urbanization is considered the concept of building a new, much more capacious and functionally saturated city on a non-large area.

The concept of organic farming as a rehabilitation of urban space sets many precedents. Examples of skyscraper farms, futuristic gardens and forests, as well as new types of eco-positive buildings equipped with Nano-skin and "living" walls, as well as other technological innovations to regulate the turnover of one of the most valuable natural resources on our planet, such as water [17].

\section{B. Information concepts: architecture of electronic-era}

In the context of information concepts, there are opportunities to use digital technologies in architectural creativity, which in turn allow the development of a direction that is associated with the concepts of virtual, fluidity, hybridity, parametric design [18].

Information directions and concepts seek to make life easier for urban people, streamline the city's structure and achieve its energy efficiency by introducing innovative "smart technologies" into urban infrastructure. Technological concepts promote the application of innovative engineering designs with the 
enrichment of the urban environment with multimedia technologies, creating a dynamic structure in which it is possible to replace individual functional elements [19].

Many project-experimental proposals provide for the organization of sensory systems that perceive external signals from the environment or inhabitants of that environment, followed by its adjustment in accordance with the data received. In this case, the design proposals "smart home" and "second skin" use a system of information security signals, allowing a person to feel comfortable in the environment.

Interactive architecture is a design area in which objects interact with each other, with space, and with humans. Objects are able to change according to changing needs or the influence of external factors. Futurology considers manifestations of interactivity such as media facades and mechanical media surfaces.

Simulation in virtual reality in architecture is used in the aspect of implementing the concept of virtual design of objects, often reflecting real reality. The virtual design applications being developed are of great interest and practical benefit to architects, becoming an important tool [20]

Parametric architecture uses the digital approach as the most sought-after for generating forms of complex geometry. Parametric design is a three-dimensional design based on the creation of a mathematical model that allows you to make changes to the parameters of the object and the ratio between them, the common algorithm that serves as the basic template for creating a specific object [21].

According to futurological projects, it is supposed to create such technological innovations as artificial intelligence, the emergence of new types of energy generation, and the development of modern computer technologies allows creating a new fantastic virtual reality. With the development of scientific and technological progress, new areas of knowledge about fractal geometry, chaos theory, and theory of non-linear systems are being involved in architectural research [22].

Searches for parametric form formation using digital technologies in the work of leading Russian and foreign architects show that computer information technology allows them to fully unleash their creative potential in a new global architectural space.

In the context of the direction in question, the architectural space of the future needs to be identified and some socio-economic concepts that are essential and require special consideration. The concept of psychophysiological comfort is aimed at reducing the level of psychophysiological tension by architectural means. Economic concepts depend on the financial capabilities of the customer and large-scale programs of the state, or various charities, (manifested in the formation of social housing, for example, the program "Affordable housing").

\section{Practical SIGNIFICANCE}

The utilitarian significance of the results of the consideration of project forecasting methods used in shaping the architectural space of the future is that for the first time a focused comprehensive study is carried out futurological experiment related to identifying innovative directions of development in architecture. Developed foundations for the formation of new generation of architectural objects, using progressive innovations, can become a generator of promising ideas, essential information, forming of modern social and cultural conditions.

\section{CONCLUSION}

As a result of consideration of emerging trends in futurological research and practical design and experimental developments, the following new approaches and innovative concepts of project forecasting in the formation of the architectural space of the future in the following directions:

1. Futurological trends and the future development of the architectural space of the future in the context of:

- Architectural futurology as a story of the future or a warning.

- Approaches to the formation of architectural space in futurology as a powerful creative stimulus: technologies for predicting the future.

- Architecture of the future: reflecting the development of science and technology as identifying "alternative opportunities" (theoretical concepts and progressive trends in architectural space).

2. The formation of a spatial habitat for the future by project forecasting methods in the context of:

- Arcological concepts as achieving a balance of technology and ecology: the formation of a "sustainable" eco-space.

- Information concepts: architecture of electronicera.

- Concepts of socio-economic development and psychophysiological comfort.

The current method of project forecasting has allowed us to outline new approaches to the development of principles of habitat formation in architecture and gives direction to searches for their prediction. It also opens up the prospect of using fundamentally new modern scientific paradigms and 
methods used for the prospective development of the spatial environment of the future.

\section{References}

[1] M.V. Fedorov, Project forecasting: structural scheme and contours of the predictive model. URL: http://ru.vlab.wikia.com/wiki/ проектное прогнозирование (accessed: 20.03.2020) [in Russian]

[2] E. Golotsan, Futurology as the story of the future in: Russian Magazine / Politics, 26.12.2001. URL: http://old.russ.ru/politics/20011226-gol-pr.html (accessed: 20.03.2020) [in Russian].

[3] A.V. Ikonnikov, Utopian Thinking and Architecture: Social, Ideological and Ideological Trends in Architecture Development, Moscow, "Arhitektura-S", 2004, 400 p. [in Russian].

[4] N.A. Saprykina, I.A. Saprykin, Predicting the future in the context of architectural retrofuturology in: Architecture and Modern Information Technologies, 2015, Special issue, pp. 1-7. URL: http://www.marhi.ru/AMIT/2015/special/sapr/sapr.pdf (accessed: 20.03.2020) [in Russian].

[5] E.V. Balatsky, Foresight technologies for the future: from complex to simple. http://futurologija.ru/bibl/balackij-e-v-texnologiipredvideniya-budushhego-ot-slozhnogo-k-prostomu (accessed: 20.03.2020) [in Russian].

[6] N.A. Saprykina, Forecasting technology as a method of modeling and building Smart City concept in: IOP Conference Series: Materials Science and Engineering (MSE), 2018, vol. 365, pp. 1-7, doi: 10.1088/1757$899 X / 365 / 2 / 022068$

[7] E.V. Balatsky, The mechanism for mutual innovation and economic growth in: Science. Innovation. Education, 2007, no. 2, pp. 87-98. [in Russian]

[8] N.A. Saprykina, I.A. Saprykin, Sustainable development of spatial habitat Environment as a challenge to civilization in: IOP Conference Series: Materials Science and Engineering (MSE), 2018, vol. 463, pp. 1-6, doi: $10.1088 / 1757-899 X / 463 / 2 / 022052$.

[9] N.A. Saprykina, Architecture of the Future: Precedents for the Formation of Space in: Architecture and construction of Russia, 2019, no. 2, pp. 38-47. [in Russian].

[10] I.A. Dobritsyna, The non-linear paradigm in the architecture of the 1990s 20th century in: Issues of architecture theory. Architectural consciousness of the 20th and 21st centuries: faults and transitions, ed. I.A. Azizian, Moscow, Scientific book, 2001, pp. 146-206. [in Russian]

[11] "Greg Lynn's Exploration of Architecture in Space", 28.04.2020. URL: http://www.evolo.us/architecture/greglynns-exploration-of-architecture-in-space/ (accessed: 20.03.2020).

[12] I.A. Dobrytsina, From postmodernism to non-linear architecture. Architecture in the context of modern philosophy and science, Moscow, Progress-Tradition, 2004, 416 p. [in Russian]

[13] S.A. Kizilova, Form and functional features of modular floating structures in: E3S Web of Conferences, 2019, no. 91. URL: https://www.e3sconferences.org/articles/e3sconf/pdf/2019/17/e3sconf_tpa cee2019_05013.pdf (accessed: 20.03.2020).
[14] N.A. Saprykina, The basics of dynamic forming in architecture, Moscow, "Architecture-S", 2018, 372 p. [in Russian].

[15] N.A. Saprykina, I.A. Saprykin, Ecological approaches to creating architectural objects as the basis for the formation of living Environment in: IOP Conference Series: Materials Science and Engineering (MSE), 2018, vol. 451, pp. 1-6, doi: 10.1088/1757899X/451/1/012131.

[16] S.A. Kizilova, The role of futurological concepts of the 20th century in the spatial organization of modular architectural objects in the aquatic environment in: Biosphere compatibility: human, region, technology, 2019, no. 3, pp. 46-54. [in Russian].

[17] N.A. Saprykina, Formation of Eco-Sustainable Rea Future: Theory of Practice Perspectives, Saarbrücken: Palmarium Academic Publishing, 2017, 232 p. [in Russian]

[18] N.A. Saprykina, Thesaurus of the parametric paradigm of architectural space formation in: Architecture and Modern Information Technologies, 2017, no. 3(40), pp 281-303. URL: http://marhi.ru/AMIT/2017/3kvart17/21_saprykina/index. php (accessed: 20.03.2020) [in Russian]

[19] D. Hant, Architecture in the "cybernetic era" in Architectural Design, 1998, no. 11-12. URL: http://www.i-

home.ru/site.xp/049055048050124051056049055124.ht $\mathrm{ml}$ (accessed: 20.03.2020) [in Russian]

[20] P. Schumacher, Parametricism - A New Global Style for Architecture and Urban Design in: AD Architectural Design - Digital Cities, 2009, vol. 79, no. 4. URL: https://patrikschumacher.com/Texts/Parametricism\%20$\% 20 \mathrm{~A} \% 20 \mathrm{New} \% 20 \mathrm{Global} \% 20$ Style\%20for\%20Architec ture\%20and\%20Urban\%20Design.html (accessed 20.03.2020)

[21] O.V. Gogolkina, Parametric Architecture in the Formation of Recreational Complexes in: IOP Conference Series: Materials Science and Engineering (MSE), 2018, vol. 463, pp. 1-6 doi:10.1088/1757-899X/463/2/022.

[22] N.A. Saprykina, New Approaches to Formation of Architectural Space: Innovative Concepts in International Conference on Architecture: Heritage, Traditions and Innovations (AHTI 2019) Advances in Social Science, Education and Humanities Research, vol. 324, pp. 376-380, doi: 10.2991/ahti-19.2019.70. 